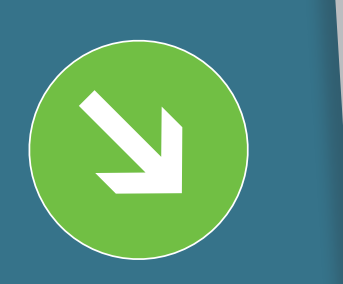

Ключевые слова: импульсный ток, прокатка, волочение, штамповка, вытяжка, плющение, ультразвуковое плющение

\section{МОДЕРНИЗАЦИЯ СТАНОЧНОГО ОБОРУДОВАНИЯ ПОД ЭЛЕКТРОПЛАСТИЧЕСКУЮ ДЕФОРМАЦИЮ МЕТАЛЛА}

\author{
Олег ТРОИЦКИЙ, ВладИМИР СТАШЕНКО
}

\begin{abstract}
Изложены основные этапы модернизации существующего станочного оборудования для перехода на энерго- и ресурсосберегающую, производительную технологию электропластической деформации металлов.
\end{abstract}

\section{ВВЕДЕНИЕ}

Формоизменение заготовок при получении продукции сопровождается сложными структурными изменениями, что требует совершенствования процессов обработки металлов давлением (ОМД). Многие материалы, применяемые в машиностроении, обладают низкой технологической пластичностью. Расширение интервала пластичности может достигаться целенаправленным влиянием на тонкую структуру металла, количество и распределение структурных несовершенств, величину внутренних напряжений, микроструктуру и свойства металла.

Решающим в формировании той или иной структуры и, следовательно, необходимых свойств металла является скорость нагрева и охлаждения [1]. Большие возможности при решении этих задач в технологиях ОМД дает применение электрического тока в зоне деформации металла. Действие электрического тока обеспечивает скоростной и равномерный нагрев заготовки в широком интервале температур, позволяет совмещать нагрев заготовки и ее деформирование, создавать условия для непрерывного, рационального, высокопроизводительного производства продукции [2-4]. Увеличение скорости нагрева значительно ускоряет диффузионное перемещение атомов углерода, улучшает очистку феррита и задерживает процесс коагуляции, сохраняя пластинчатую форму цементита, что является обязательным условием для больших суммарных обжатий $[1,4]$. Дополнительным резервом повышения пластичности деформируемых конструкционных материалов является применение импульсного тока высокой плотности.
Целью работы является описание способов модернизации станочного оборудования под электропластическую деформацию металла.

Пластифицирующее действие импульсного тока на деформацию металла (электропластический эффект - ЭПЭ) было обнаружено примерно 50 лет назад при растяжении или сжатии монокристаллов цинка в жидком азоте и описано в работе [5]. Эффект проявлялся в виде скачков пластической деформации в импульсах тока [6]. Он был подтвержден американскими учеными на поликристаллическом титане [7-9]. Для реализации ЭПЭ при любом виде обработки металлов давлением должны выполняться следующие условия:

$\rightarrow$ заготовка должна находиться под механическими напряжениями выше предела текучести $\sigma_{c}$;

$\rightarrow$ импульсный ток низкого напряжения (20-25 B) и высокой плотности $J_{m}$ должен подаваться непосредственно в зону деформации;

$\rightarrow$ форма импульсов должна быть прямоугольной или трапецеидальной;

$\rightarrow$ длительность импульсов $\tau$ должна иметь значения примерно $10^{-4}$ с, то есть не превышать времени $10^{-3}$ с обычных скачков деформации, чтобы не возникал значительный сопутствующий нагрев;

$\rightarrow$ амплитудная плотность тока $J_{m}$ должна быть большой, не менее $10^{5} \div 10^{6} \mathrm{~A} / \mathrm{cm}^{2}$, чтобы электроны проводимости приобретали значительные дрейфовые скорости $v_{e}$ порядка одного метра в секунду (скорость «электронного ветра») в соответствии с формулой

$$
v_{e}=J_{m} / e \cdot n,
$$


(где $e$ и $n$ - заряд и концентрация свободных электронов) и смогли бы передавать на дислокации и другие подвижные дефекты структуры импульсы силы и энергии;

$\rightarrow$ частота следования импульсов $F$, определяемая формулой $F=k \cdot v_{\text {дв }} / \Delta l$, где $v_{\text {дв }}$ - скорость движения заготовки, $\Delta l$ - протяженность зоны деформации и $k$ - коэффициент порядка двух (два импульса на $\Delta l$ ), должна составлять несколько сотен Гц, чтобы гарантировать проработку импульсным током всех участков заготовки.

Действие ЭПЭ во время ОМД дает следующие результаты:

$\rightarrow$ сопротивление металла деформированию снижается на 25-30\%;

$\rightarrow$ увеличивается пластичность металла во время обработки;

$\rightarrow$ повышается степень совершенства аксиальной текстуры проволоки при волочении, ее электрическое сопротивление снижается на 15-20\%, улучшается структура и фазовый состав материала проволоки;

$\rightarrow$ при прокатке, волочении и вытяжке нержавеющих сталей практически полностью подавляется аустенитно-мартенситное фазовое $\gamma-\alpha-$ превращение, что делает ненужными операции дорогостоящих и энергоемких аустенизирующих отжигов заготовок;

$\rightarrow$ уменьшается вероятность хрупкого разрушения материала заготовки во время обработки.

В основе ЭПЭ лежит силовое действие тока на пластическую деформацию металла по двум каналам - через электронную подсистему посредством воздействия «электронного ветра» на дислокации, а также через решеточную подсистему металла посредством создания вибрации решетки за счет пинч-действия импульсного тока (взаимодействия импульсного тока с собственным магнитным полем тока). В силу действия последнего физического фактора возникают колебания узлов решетки, подобные тем, что имеют место при действии ультразвуком на пластическую деформацию металла по механизму своеобразного механотронного действия, не связанного с тепловым действием тока [6].

\section{ЭЛЕКТРОПЛАСТИЧЕСКОЕ ВОЛОЧЕНИЕ (ЭПВ)}

Для осуществления ЭПВ можно использовать схемы подведения электрического тока к проволоке, изображенные на рис. 1. Схемы $a$ и в позволяют осуществлять истинную технологию ЭПВ с пропусканием тока через участок проволоки, включающий очаг деформации, с применением твердосплавной или алмазной волоки. По схеме б можно изучать влияние нагрева проволоки током на процесс ее волочения, а по схеме г- влияние вибраций метал-
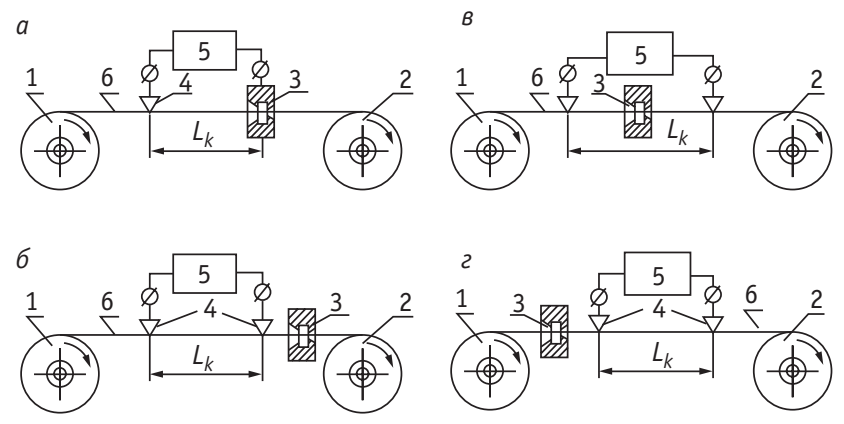

Puc. 1. Схемы подведения тока к движущейся проволоке во время волочения: 1 - сдаточная катушка; 2 - приемная катушка; 3 - волока;

4 - скользящие контакты; 5 - источник тока;

6 - проволока. $l k$ - участок действия тока

ла за счет пинч-эффекта, свойственного импульсному току. В последнем случае пондеромоторные силы, возникающие за волокой за счет пинч-эффекта (в результате взаимодействия тока с собственным магнитным полем), вызывают упругие механическиеколебания проволоки, которые распространяются вдоль проволоки до зоны деформации, где они оказывают свое стимулирующее действие на пластическую деформацию металла, но уже без электронной компоненты электропластического действия тока.

Для однократного волочения проволоки диаметром 0,5 мм и менее по технологии ЭПВ можно использовать волочильный станок типа F-1 «Кратос», а для диаметров 1,5-0,2 мм однократный волочильный стан ПТ-1 типа 1/160, 250 (см. рис. 2).

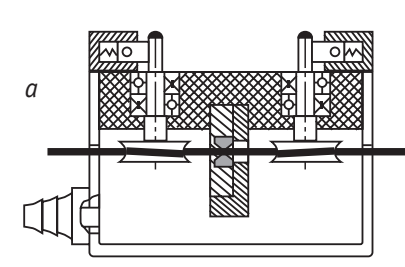

Puc. 2.

Реализация технологии ЭПВ: $a$ - блок с токоподводами и волокой, 6 - стан однократного волочения проволоки

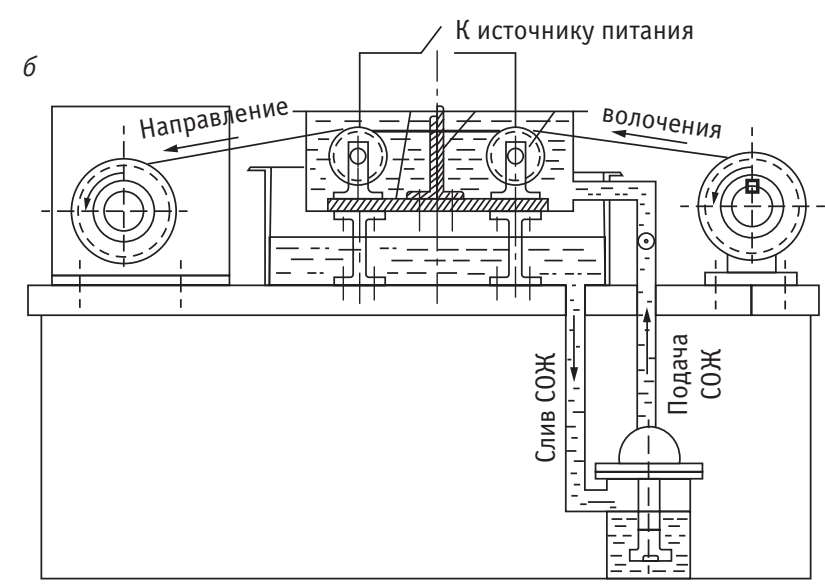


Для большей части металлов (меди, вольфрама и молибдена) эффект снижения усилий волочения максимален при подключении плюса источника тока до зоны деформации, когда направление тока электронов проводимости совпадает с направлением движения зоны деформации (рис. 3).

Эффект действия тока максимален при малых скоростях волочения проволоки $\mathrm{v}_{\mathrm{B}} \leq 0,1 \mathrm{~m} / \mathrm{c}$, имеет указанную выше минимальную величину при средних скоростях волочения $\mathrm{v}_{\mathrm{B}}=0,3-0,5 \mathrm{M} / \mathrm{c}$ и исчезает при больших скоростях волочения $\mathrm{v}_{\mathrm{B}} \geq 1,0 \mathrm{~m} / \mathrm{c}$, при которых нарушается основное условие существования электропластического эффекта (ЭПЭ), а именно превышение скорости дрейфа электронов $v_{\mathrm{e}}$ над скоростью деформации металла $v_{\mathrm{B}}$, то есть $v_{\mathrm{e}} \geq \mathrm{v}_{\mathrm{B}}$.

Предельно допустимая техническими нормами плотность тока в медных проводах составляет $j_{m}=10^{3} \mathrm{~A} / \mathrm{cm}^{2}$. Этому соответствуют значения скорости дрейфа электронов $0,1 \mathrm{~cm} / \mathrm{c}$.

Реально в полупромышленных экспериментах плотностям импульсного тока $(0,35-0,5) \cdot 10^{6} \mathrm{~A} / \mathrm{cm}^{2}$ соответствовали значения дрейфовых скоростей электронов $v_{\mathrm{e}}=0,35-0,5 \mathrm{~m} / \mathrm{c}$. Таким образом, применимость ЭПЭ для интенсификации процесса волочения металла несомненна. Тем более, что второе условие существования ЭПЭ, а именно превышение механическими напряжениями волочения $\sigma_{\mathrm{B}}$ значений предела текучести металла $\sigma_{\mathrm{T}}$ во время ЭПВ априори выполняется.

Величина эффекта действия тока при ЭПВ растет с увеличением частоты, длительности импульсов, амплитудной и средней плотности тока.

Во время ЭПВ на тонких проволоках выделяемая в зоне волочения мощность тока не превышает 100 Вт. Таким образом, энергетические затраты при ЭПВ незначительны и находятся на уровне мощности,

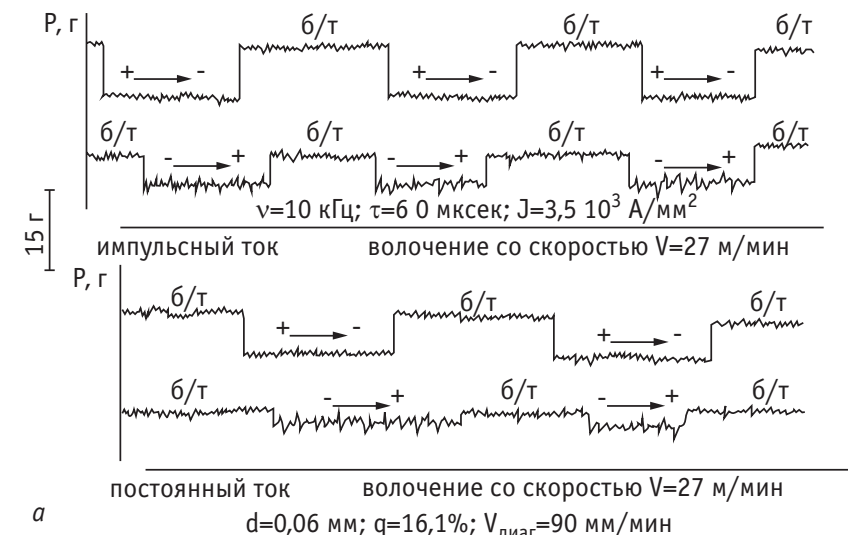

потребляемой одной лампочкой накаливания, что обусловлено высокой локализацией зоны действия.

В результате ЭПВ проволоки из нержавеющей стали происходит резкое снижение содержания мартенситной $\alpha$-фазы: после 8-10 переходов на проволоке диаметром 0,3 мм оно не превышает 6-8\%, а после обычного волочения составляет $60-70 \%$. Оставшаяся после ЭПВ $\alpha$-фаза выделяется преимущественно у поверхности проволоки, образуя рубашку толщиной в несколько микрон.

Пластичность проволоки $\delta$ (относительное удлинение) из метастабильной аустенитной стали (МАC) в результате ЭПВ увеличивается на $40 \%$, что больше результатов испытаний образцов после теплого волочения (20-25\%) и тем более после холодного волочения (5-6\%). Трип-эффект на проволоке из МАС, прошедшей ЭПВ, увеличивается более, чем в два раза на импульсном токе и в полтора раза - на постоянном токе по сравнению с теплым волочением.

\section{ЭЛЕКТРОПЛАСТИЧЕСКАЯ ПРОКАТКА (ЭПП)}

По характеру напряженного состояния заготовки и направлению движения пластических зон во время прокатки сопутствующий ток электронов во время ЭПП можно создавать, пропуская ток от валка к валку через заготовку (рис. 4 a). При этом усилия прокатки снижаются на 20-25\%. Однако этот способ подведения тока не позволяет осуществлять ЭПП при больших скоростях прокатки, он совершенно непригоден для толстых заготовок и сопряжен с возникновением электроэррозионных процессов на валках. Кроме того, при указанном способе ЭПП валки необходимо изолировать друг от друга и от стана. Наконец, невозможно осуществить комбинацию ЭПП и ЭКН (электроконтактный нагрев) для предварительной тепловой подготовки заготовки. Поэтому

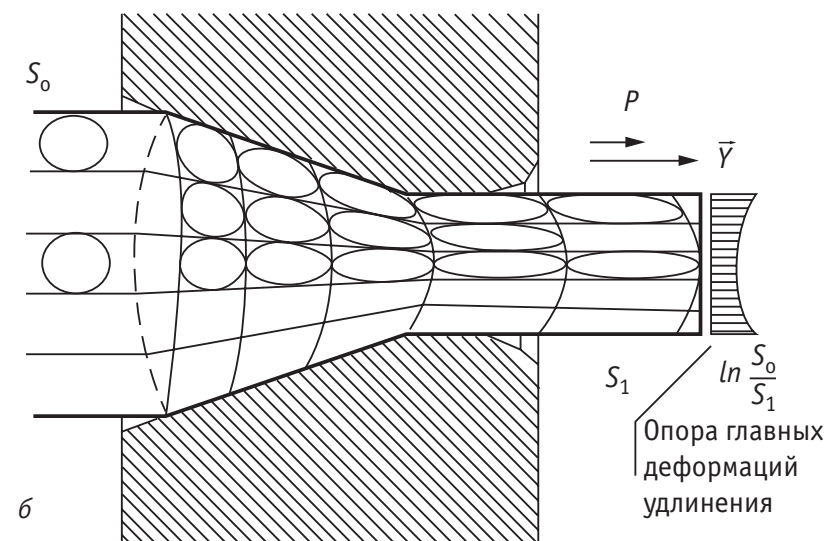

Puc. 3. Волочение при подключении плюса источника тока до зоны деформации: $a$ - характерные диаграммы изменения усилий волочения $P$ при волочении 60 мкм медной проволоки с наложением на зону деформации электрического тока различной полярности и разного вида, б - формирование совершенной текстуры проволоки во время ЭПВ при совпадении направления вектора плотности тока $J_{m}$ с направлением движения проволоки 
этот способ ЭПП можно рекомендовать для получения лишь нешироких лент из тонких проволок и очень тонкого листового материала, а также получения плющенки из тонкой проволоки с током.

При подведении тока к заготовке специальными контактами до и после зоны деформации (рис. 4 б) валки вообще исключаются из электрической цепи, не требуется капитальной перестройки стана и можно комбинировать ЭПП и ЭКН. Кроме того, указанный способ ЭПП не имеет ограничений по толщине заготовки. Единственным его недостатком является то, что электропластический эффект не реализуется полностью, так как линии тока совпадают полностью с направлением движения зон пластического течения металла между валками.

Способ подведения тока (рис. 4 в) одним полюсом через скользящий контакт до зоны деформации заготовки между валками, а вторым полюсом через валки (1 - деформирующий опорный вал; 2 - скользящие контакты) характеризуется тем, что подведение тока минимизирует участок заготовки, находящийся под током, также исключается возможность перегрева металла и снимаются ограничения по толщине прокатываемого листа (полосы или ленты). При подведении тока к заготовке передним скользящим или роликовым контактом и через рабочие валки осуществляется комбинация ЭПП и ЭКН. Усилия прокатки снижаются на 30-35\%, но валки остаются под действием тока. Были определены оптимальные режимы импульсного тока: амплитудная плотность тока $J_{m}$ порядка 500-600 A/мм²; длительность импульсов 150 мкс и частота следования импульсов 500 Гц. Следует отметить, что в результате ЭПП для разных металлов происходило уширение ленты (до 15-20\%) при значительных единичных обжатиях, а длина образцов уменьшалась по сравнению с образцами, проходившими прокатку без тока.

Технологию ЭПП целесообразно вводить на существующих прокатных станах при низких и средних (не более $0,5 \mathrm{~m} / \mathrm{c}$ ) скоростях прокатки, либо осуществлять высокоскоростную ЭПП на очень тонких заготовках.
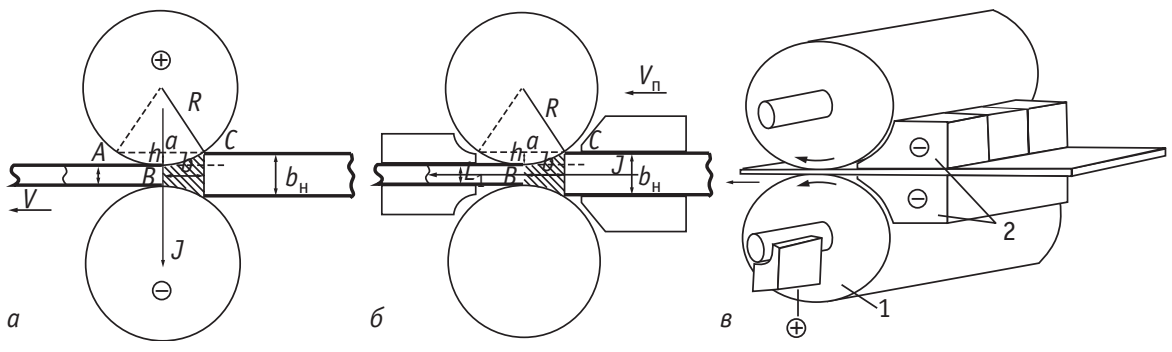

Puc. 4. Способы подведения тока: $a$ - от валка к валку, б - через заготовку, в - от заготовки к валку
При электропластической прокатке:

$\rightarrow$ производительность станов повышается в 1,5 раза;

$\rightarrow$ устраняются операции промежуточных отжигов;

$\rightarrow$ уменьшается анизотропия материала;

$\rightarrow$ энергопотребление приводами прокатных станов уменьшается на $25-30 \%$;

$\rightarrow$ повышается остаточная пластичность заготовок;

$\rightarrow$ длина заготовок увеличивается на $10-15 \%$ за счет сокращения их ширины;

$\rightarrow$ подавляются нежелательные структурно-фазовые превращения.

Проведенные полупромышленные эксперименты показали, что при плющении тонких заготовок в виде проволок диаметром менее 1 мм из вольфрама, стали и пружинного сплава К40ТЮ в процессе ЭПП получается лента с высоким качеством поверхности и кромок, с высокими физико-механическими свойствами. В образцах из нержавеющей стали в результате действия тока во время ЭПП подавляется структурно-фазовое $\gamma-\alpha$-превращение, что согласуется с результатами по ЭПВ стальной проволоки.

\section{ЭЛЕКТРОПЛАСТИЧЕСКАЯ РОТАЦИОННАЯ ВЫТЯЖКА (ЭПРВ)}

Сущность ротационного выдавливания (вытяжки) состоит в том, что в качестве инструмента применяется серия шариков, расположенных по периметру формируемой детали и заключенных в единую обойму - матрицу шариковую. Процесс деформирования состоит из последовательного наложения локальных деформаций осадки и вытяжки элементарных объемов цилиндрической заготовки давлением шариков и в последующем суммировании этих деформаций в процессе перемещения шаров с шагом (подачей) и глубиной обжатия а $=\delta_{0}-\delta$, где $\delta_{0}$ и $\delta-$ толщина стенки до и после обжатия. При этом материал заготовки деформируется по спирали и выдавливается (вытягивается) в зазор между оправкой (пуансоном) и шариком. Локальный характер очага деформации в условиях вращения деформирующего инструмента обеспечивает возможность деформирования детали с меньшим усилием, чем глубокая вытяжка (рис. 5). Механизм сохранения структуры и небольшого упрочнения металла при ротационной вытяжке рубашек в режиме электропластической ротационной вытяжки при спиральном перемещении шариковой оснастки объясняется минимальными нагрузками каждого отдельного шарика на свою зону металла со сдвигом под некоторым углом. Указанное обстоятельство обеспечи- 

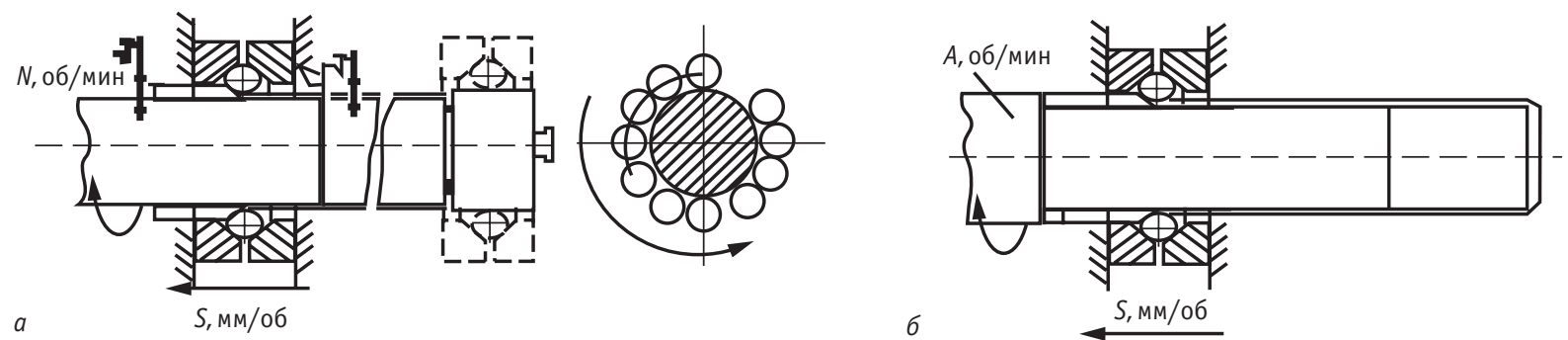

Puc. 5. Ротационная вытяжка металлов с током на сотни процентов без отжигов

вает уход от лобового сопротивления всей заготовки и более полное использование ЭПЭ. Указанная ситуация постоянно воспроизводится при импульсной токовой подпитке шарикового инструмента и обрабатываемого материала. При этом перед обоймой с деформирующими шариками вдоль заготовки перемещается волна металла, что фиксировалось автором экспериментально при остановках вытяжки в середине процесса.

\section{ЭЛЕКТРОПЛАСТИЧЕСКАЯ ШТАМПОВКА (ЭПШ)}

В результате электропластической штамповки повышается статическая прочность материала изделия $\sigma_{\text {в }}$ (временное сопротивление), предел выносливости $\sigma_{-1}$ и ресурс циклического нагружения без снижения пластических свойств материала (стали 12Х18Н10T, 30ХГСА, титановых сплавов ВТ8, ОТ4 и ВТ20, а также алюминиевых сплавов Д16 и АМг6).

Происходит также снижение остаточных напряжений 1-го рода и полное исчезновение остаточных напряжений 2-го рода. По данным О. Попова, ЭПШ с успехом может быть применена для интенсификации технологических операций листовой штамповки тонкостенных деталей обшивки планера летательных аппаратов. В заготовку, установленную в технологическую оснастку, импульс тока до начала формообразования вводится только в том случае, если необходима тепловая подготовка и предварительное повышение пластичности материала, то есть комбинация ЭПШ с ЭКН. Первый рабочий импульс тока вводится в момент достижения деформацией значений $\varepsilon_{i}=(0,25-0,7) \cdot \varepsilon_{\text {пр }}$, где $\varepsilon_{\text {пр }}$ - предельная степень деформации при штамповке без тока, соответствующая моменту разрушения заготовки или поте- ри ею устойчивости. Последующие импульсы по мере необходимости вводятся в моменты очередных возрастаний деформации до величины $\varepsilon_{i}$. Последний импульс вводится при величине деформации, меньшей $\varepsilon_{\mathrm{K}}$ на величину $\varepsilon_{i}$. Поэтому на последнем этапе ЭПШ за счет деформационного упрочнения получаются равнопрочные детали. При осуществлении по технологии ЭПШ специфической для авиационного производства операции подсечки угловых профилей (рис. 6 a) установлено, что максимальная степень деформации, определяемая отношением высоты подсечки $h$ к длине ее сбега $L$, за счет ЭПШ превышает соответствующие показатели, полученные без тока в 2-3 раза. При этом точность изготовления подсечек соответствует точности изготовления штампа. При гибке профилей с растяжением (рис. 6 б) ток вводится по концам заготовки с помощью специальных зажимов-контактов, изолированных от массы. В результате ЭПШ полностью устраняется пружинение и получаются качественные детали из сплавов ВТ4М, ВТ20М, 1420 и В95чТ. При продольной протяжке обшивок двойной кривизны из сплавов В95ПчАМ и 1420 методом ЭПШ получаемые модельные обшивки характеризовались высокой точностью и пружинение полностью отсутствовало. Аналогичные результаты дает применение ЭПШ при поперечной обтяжке (рис. 6 в) модельных обшивок двойной кривизны из сплавов ОТЧ и ВТ20М.

\section{УЛЬТРАЗВУКОВОЕ ЭЛЕКТРОПЛАСТИЧЕСКОЕ ПЛЮЩЕНИЕ (УЗЭП)}

Способ предусматривает одновременное использование в зоне деформации электрического тока и ультразвука, как показано на (рис. 7), где 1,9 -
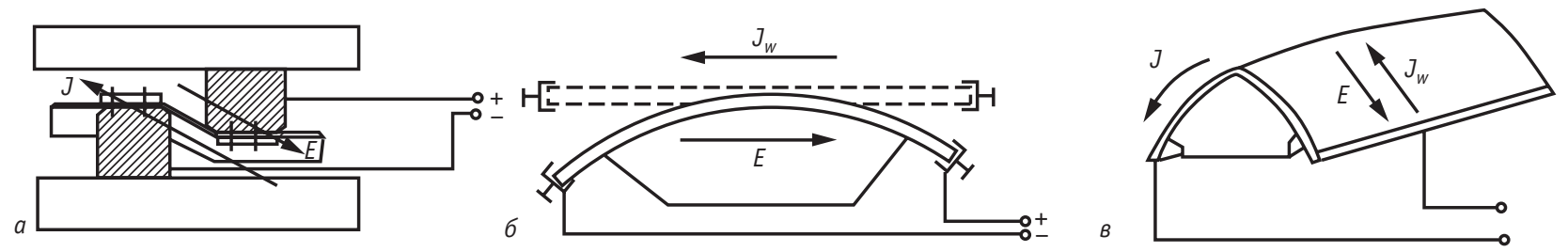

Puc. 6. Штамповка металла с током без отжигов: $a$, б - подсечка и гибка с растяжением; в - поперечная обтяжка 


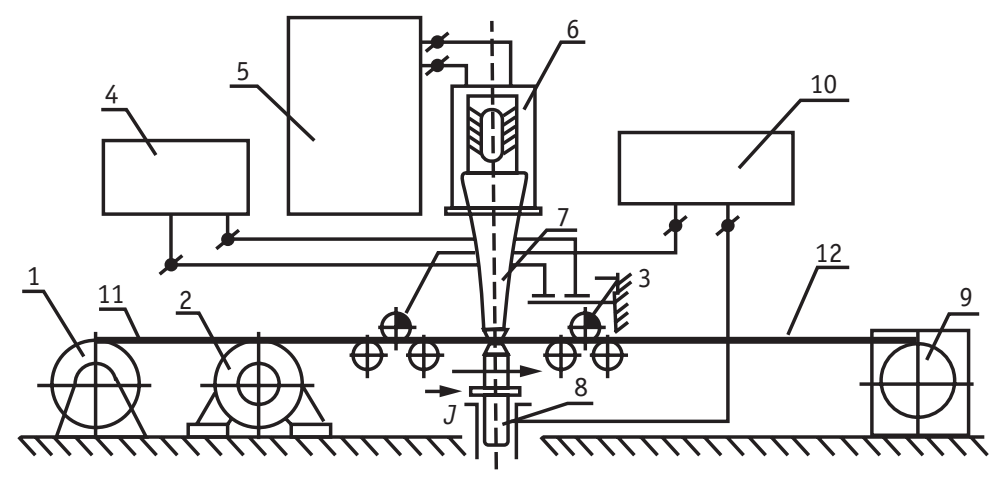

Puc. 7. Установка ультразвукового электропластического плющения труднодеформируемых металлов и сплавов из проволоки в ленту микронных размеров

приемно-сдаточный и укладочный механизмы; 2 двигатель постоянного тока; 3, 4 - датчик натяжения и тензостанция; 5, 6 и 7 - ультразвуковой генератор, преобразователь и концентратор УЗ-колебаний; 8 - отражатель; 10 - генератор импульсного тока; 11 - исходная проволока; 12 получаемая микролента.

Установлено, что при УЗЭП проволоки вольфрама в ленту микронных размеров по толщине достигаются единичные обжатия до 88-90\% при хорошем качестве поверхности и кромок ленты, имеющей ширину порядка 1 мм. Лента обладает высокой пластичностью, может производиться без создания защитной атмосферы вокруг зоны деформации.

Наложение тока на зону деформации пружинной ленты из сплава К40ТЮ приводит к росту угла пружинности ленты $\Psi$, более раннему по степеням деформации упрочнению $\sigma_{\text {в }}$ и некоторому росту числа $n$ гибов ленты. Происходит также увеличение параметра кристаллической решетки основной фазы, что объясняется выделением мелкодисперс-

\section{Рынок}

- Мировой рынок только формируется.

- Российский рынок в начале становления.

- Есть предпосылки к глобальному росту.

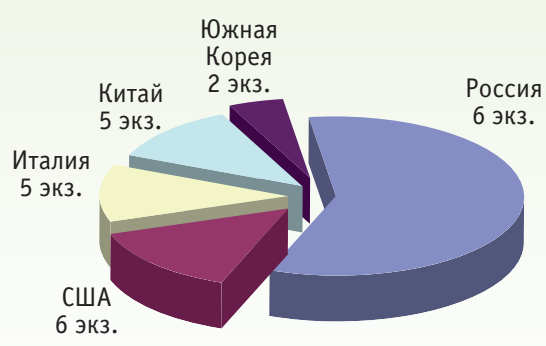

Количество единиц металлообрабатывающего оборудования, работающего по технологии ЭПдМ

Puc. 8. Оборудование, работающее по технологии ЭПДМ ных фаз и образованием сложных твердых растворов.

\section{ЗАКЛЮЧЕНИЕ}

В настоящее время на основе ЭПЭ в разных странах (в основном в России, Южной Корее, Италии, Великобритании и Китае) создано примерно 45 единиц станов и мощных металлообрабатывающих станков, работающих по технологиям ЭПДМ (рис. 8). Разрабатываются различные варианты эффективных энергосберегающих критических технологий ЭПДМ прокаткой, волочением, штамповкой, вытяжкой и плющением.

\section{ЛИТЕРАТУРА}

1. Кидин И.Н. Фазовые превращения при ускоренном нагреве стали. - М.: Металлургия, 1957. $280 \mathrm{c}$.

2. Романов Д. И. Электроконтактный нагрев металлов. - М.: Машиностроение, 1975. 250 с.

3. Сташенко В.И., Троицкий О.А. Влияние формы и режимов прохождения импульсов тока на пластическую деформацию кристаллов цинка // Докл. АН СССР. 1982. Т. 267. № 3. 638 с.

4. Хасин Г.А., Данова А.И., Попова Т. Н. и др. Электротермическая обработка и теплое волочение стали. - М.: Металлургия, 1984. 149 с.

5. Троицкий О.А. Электромеханический эфрфект в металлах // Письма в ЖЭТФ. 1969. Т. 2. № 10. С. 18-22.

6. Троицкий О.А., Баранов Ю. В., Авраамов Ю.С. и Шляпин А. Д. Физические основы и технологии обработки современных металлов: в 2-х т. - М. Ижевск: Изд-во РХД, АНО ИКИ.

8. Okazaki K., Kagava M., Conrad H. Electroplastic effect in metals, Scr. Met.,12, 1978. C. 1063.

9. Okazaki K., Kagava M., Conrad H. Scr. Met., 13, 1979. C. 277.

10. Okazaki K., Kagava M., Conrad H. Scr. Met., 13, 1979. C. 473.

тРоицкий Олег Александрович -

доктор технических наук, главный научный сотрудник, Федеральное государственное бюджетное учреждение науки «Институт машиноведения им. А.А. Благонравова РАН»

\section{СТАШЕНКО Владимир Иванович -}

кандидат физико-математических наук, ведущий научный сотрудник, Федеральное государственное бюджетное учреждение науки «Институт машиноведения им. А.А. Благонравова РАН» 